\title{
Hyalella dielaii sp. nov. from São Paulo, Brazil (Amphipoda, Hyalellidae)
}

\author{
Vania F. Goulart C. Pereira \\ Departamento de Ciências Básicas, Faculdade de Medicina Veterinária, Fundação Educacional D. André Arcoverde. \\ Rua Sargento Vitor Hugo 161, Bairro de Fátima, 27600-000 Valença, Rio de Janeiro, Brasil. E-mail: f.goulart@uol.com.br
}

\begin{abstract}
Hyalella dielaii sp. nov., from São Paulo, Brazil, is herein described and illustrated. Dorsal margin of single ramus of uropod 3, with two marginal groups of three spines, is the main diagnostic characteristic for this new species. Among other distinctive features that may help to distinguish it are the inner plate of the maxilla 1 distinctly long and thin and the dactylus very short of male gnathopod 2 very short.

KEY WORDS. Crustacea, freshwater anfipods, taxonomy.
\end{abstract}

RESUMO. Hyalella dielaii sp. nov., encontrada em São Paulo, Brasil, é aqui descrita com ilustrações. O urópodo 3 com dois grupos de três espinhos na margem dorsal do ramo único, é a principal característica diagnóstica para esta nova espécie. Entre outras características específicas, o ramo interno da maxila 1 distintamente longo e delgado e o dáctilo curto do gnatópodo 2 do macho, também auxiliam na caracterização.

PALAVRAS CHAVE. Anfípodo de água doce, Crustacea, taxonomia.

Most species of the family Hyalellidae Bulycheva, 1957, are freshwater inhabitants, only a few are marine. The genus Hyalella Smith, 1874, encompasses exclusively freshwater species widespread in temperate and tropical American regions, all occurring in habitats ranging from small freshwater pools to rivers and large lakes, both in cold and in warm waters.

According González \& Watling (2003), nine species of Hyalella have been found in Brazil: $H$. brasiliensis Bousfield, 1996; H. caeca Pereira, 1989; H. curvispina Shoemaker, 1942; H. gracilicornis (Faxon, 1876); H. longistila (Faxon, 1876); H. meinerti Stebbing, 1899; H. montenegrinae Bond-Buckup \& Araújo, 1998; Hyalella pseudoazteca González \& Watling, 2003; and $H$. warmingi Stebbing, 1899. SoARes (1977) announced the occurrence of the genus on Itamaracá Island, Pernambuco, northeast of Brazil.

The present study describes a new species of Hyalella collected in Alto da Serra, São Paulo, Brazil.

\section{MATERIAL AND METHODS}

The material examined is deposited in the collection of the Invertebrates Department of the Museu Nacional, Universidade Federal do Rio de Janeiro (MNRJ), Brazil.

Type material. Museu Nacional. Holotype a male and allotype female: MNRJ 9538, 6273, Alto da Serra, São Paulo, 05/X/1960, Risilho leg.; Paratypes: MNRJ 6272, 2 males and 4 females, Alto da Serra, São Paulo, 05/X/1960, Risilho leg.; MNRJ 9537, 1 male and 2 females, Alto da Serra, São Paulo, 17/XI/ 1960, Risilho leg.

\section{Hyalella dielaii sp. nov.}

Figs 1-18

Hyalella serrana Bousfield, 1993: 221; González \& Watling, 2003: 2045; nomen nudum.

Diagnosis. Adult male, length 3.3-6.7 mm.

Body surface smooth. Cephalothorax same size as first pereonite, with small, black, round eyes (Fig. 1). Coxal plates distally rounded, increasing gradually in size from the first to the fourth, the last one with a crescent-shaped cleft; from pereionites 5 to 7 , coxal plates presenting small setae on the posterior margin; first pereonite with rounded posterior angle in lateral view, approximately one-third of the length of the other two, which have acute posterior angles (Fig. 1). Sternal gills present from $2^{\text {nd }}$ to $7^{\text {th }}$ pereon somite, the $2^{\text {nd }}$ and $7^{\text {th }}$ gills being very slender. Accessory gills present on the $3^{\text {rd }}, 4^{\text {th }}$ and the $6^{\text {th }}$ pereon somites.

Antennula shorter than antenna, slightly longer than peduncule of the antenna, reaching the end of the first thoracic somite when drawn back; flagellum approximately 1.5 times as long as peduncle, with 15-17 segments, all with setose articulations (Fig. 2).

Antenna reaching the posterior margin of the pereonite 4 when drawn back; peduncle with setose articulations, $5^{\text {rd }}$ article longer than others; flagellum with 18 to 22 segments, approximately 1.5 times as long as peduncle, with setose articulations (Fig. 3).

Mouthparts. Upper lip rounded with setose distal surface (Fig. 4). Lower lip bilobate, inner and apical margins with

Revista Brasileira de Zoologia 21 (2): 179-184, junho 2004 


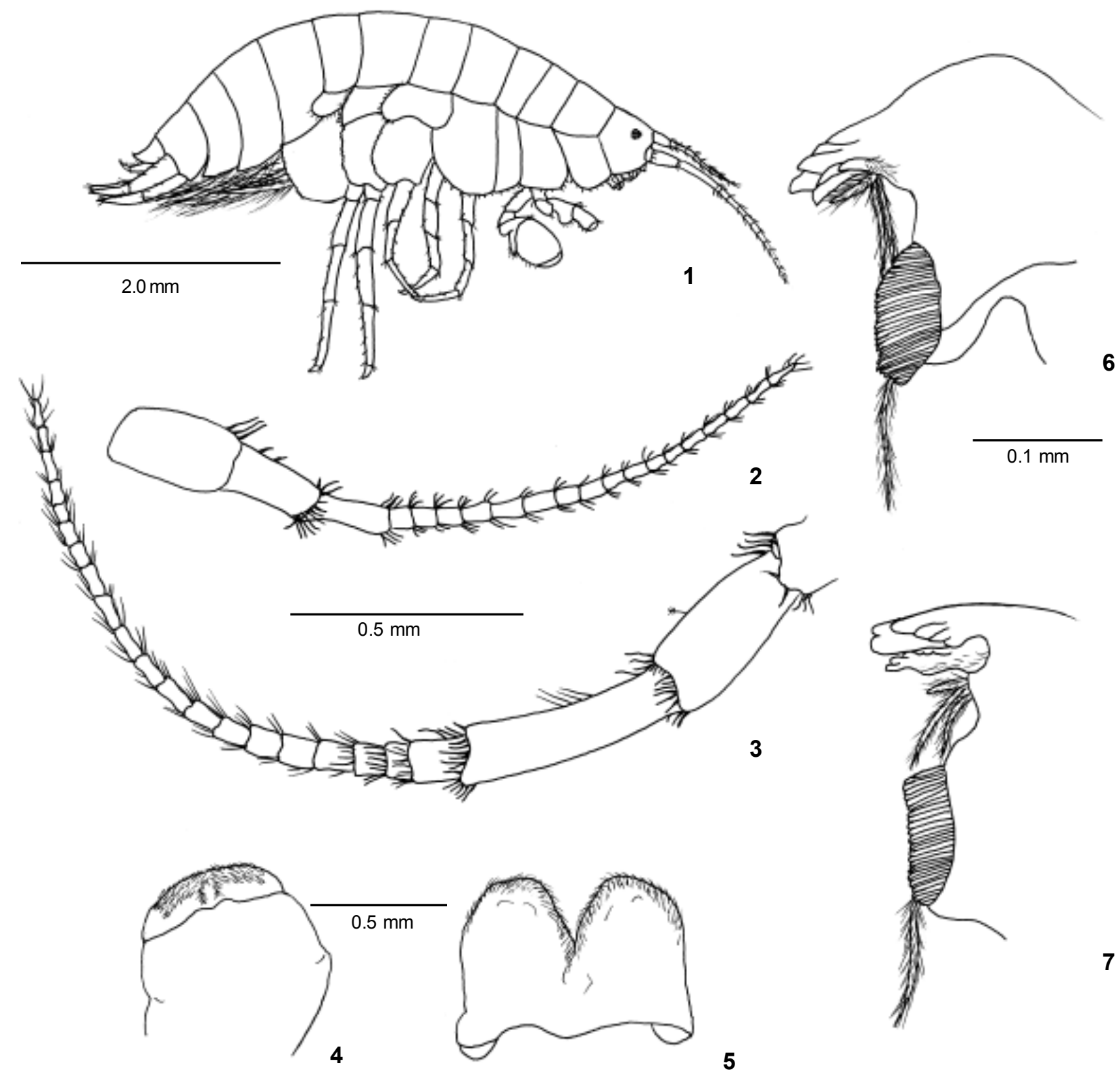

Figures 1-7. Hyalella dielaii sp. nov., male: (1) body of specimen adult; (2) antennula; (3) antenna; (4) upper lip; (5) lower lip; (6) right mandible; (7) left mandible. Scale bars: $1=2.0 \mathrm{~mm}, 2-5=0.5 \mathrm{~mm}, 6-7=0.1 \mathrm{~mm}$.

thin setae (Fig. 5). Right mandible incisive process with seven cusps and three plumose setae, one of these being small but robust; penicilium present on molar process (Fig. 6). Left mandible similar to right one, except having incisive process with six cusps and lacinia with six cusps (Fig. 7). Maxilla 1 inner plate slender and without marginal setae, about 8 times longer than wide, length about 0.75 of outer ramus, with two strong and plumose apical setae at its truncated apex; outer plate with nine stout and serrate setae; palp uniarticulate, minute, with delicate setae on outer margin and distal setae strong, about half the length of the article (Fig. 8). Maxilla 2 inner plate distal margin with plain and bipectinate setae, inner subdistal margin with two plumose setae; outer plate subequal in length to palp, with numerous simple, long, curved setae, one bipectinate setae in apical region, a short thin, plain seta at inner medial margin; outer and inner plates with scarce plain

Revista Brasileira de Zoologia 21 (2): 179-184, junho 2004 

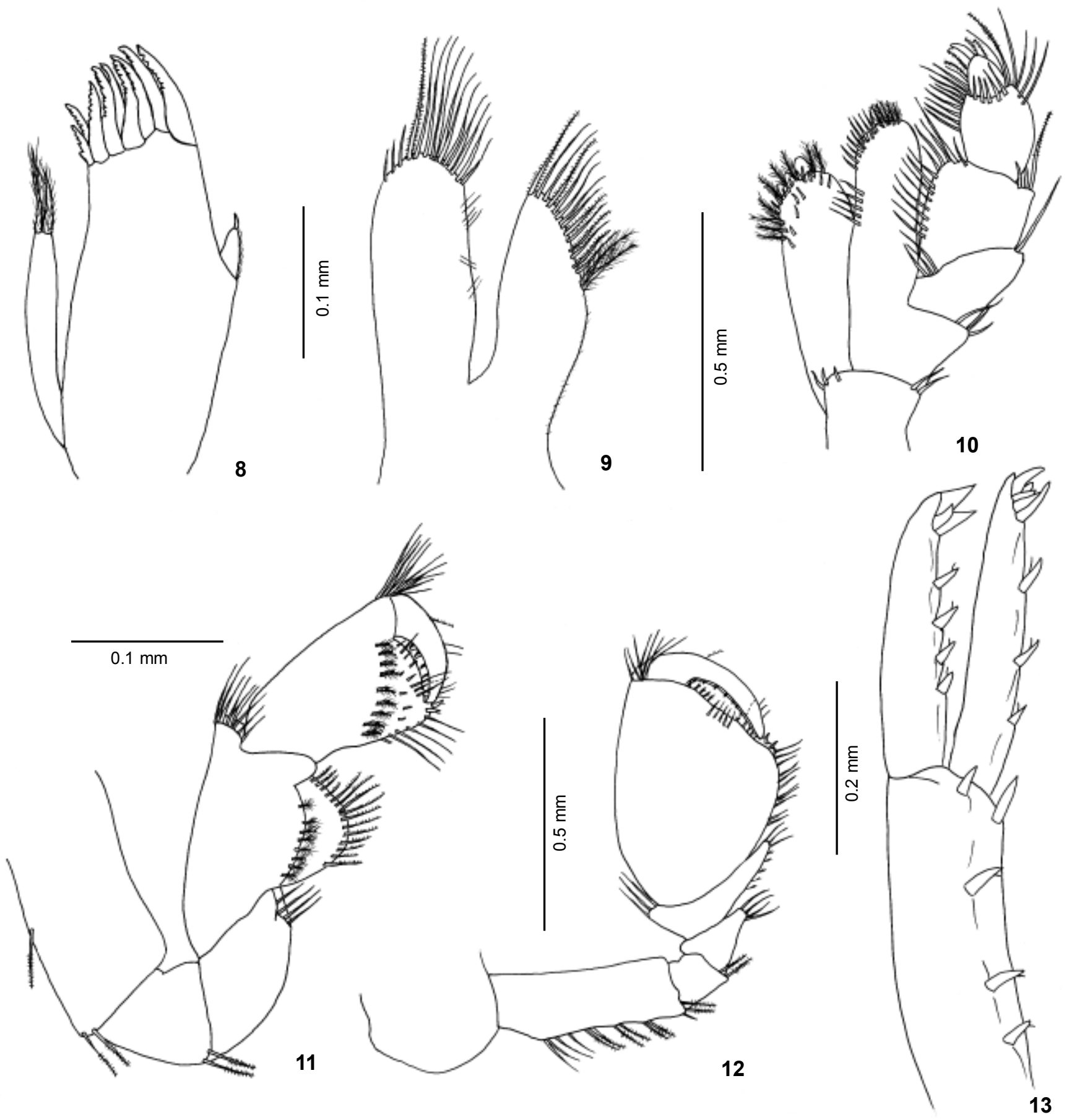

Figures 8-10. Hyalella dielaii sp. nov., male: (8) maxilla 1 ; (9) maxilla 2; (10) maxilliped; (11) gnathopod 1; (12) gnathopod 2; (13) uropod 1. Scale bars: $8-9=0.1 \mathrm{~mm}, 10=0.5 \mathrm{~mm}, 11=0.1 \mathrm{~mm}, 12=0.5 \mathrm{~mm}, 13=0.2 \mathrm{~mm}$.

setules (Fig. 9). Maxilliped inner plates apically truncated, with three connate setae, increasing in size from the inner to the outer one, with apical, medial and facial plumose setae and spines; outer plates with medial and facial setae simple and spines, five plumose apical setae and 3-5 long setae at medial margin; basis outer distal margin with two simple setae and 


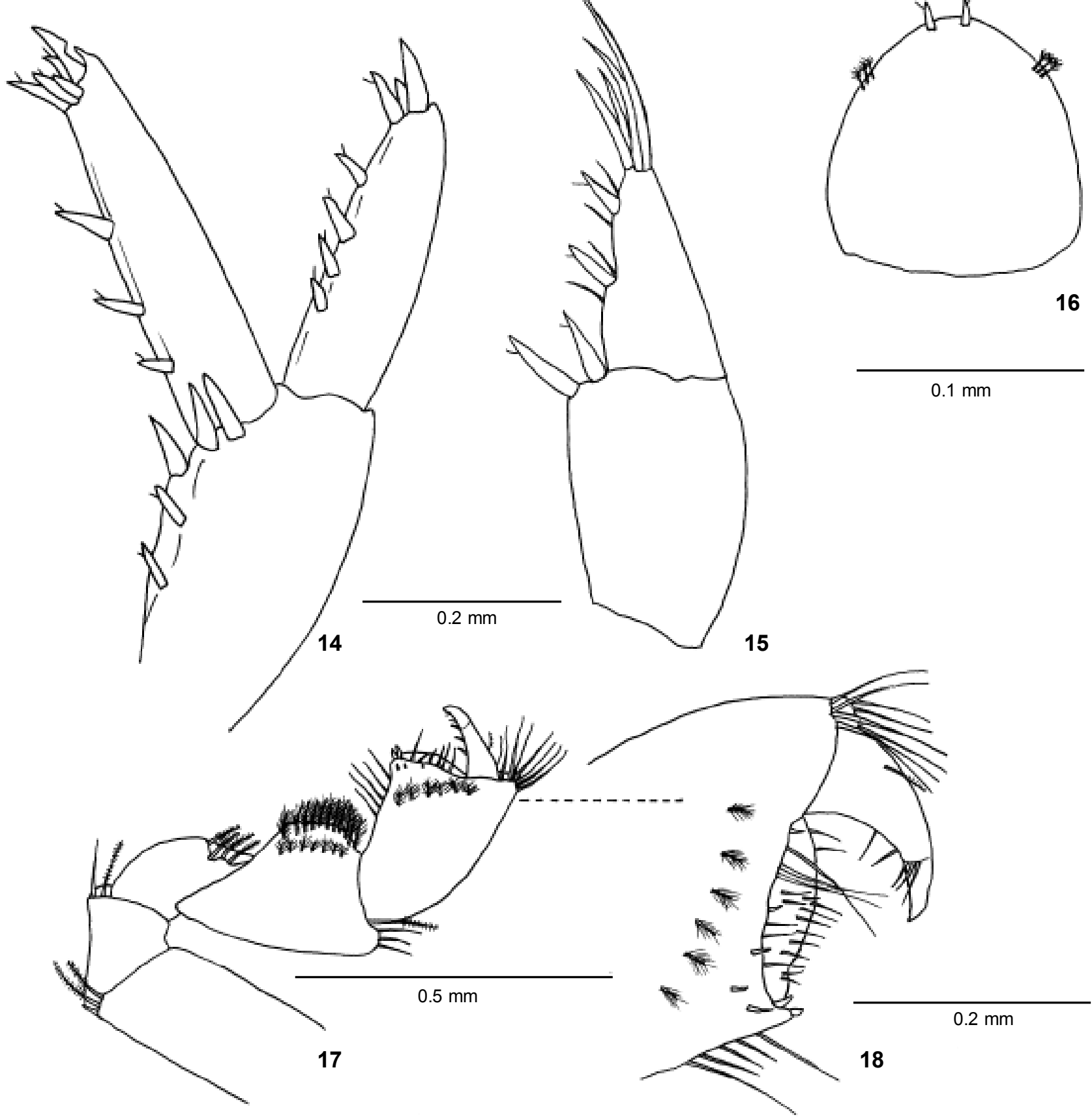

Figures 14-18. Hyalella dielaii sp. nov. (14-16) Male: (14) uropod 2; (15) uropod 3; (16) telson. (17-18) Female: (17) gnathopod 1; (18) gnathopod 1, palm. Scale bars: $16=0.1 \mathrm{~mm}, 14,15,18=0.2 \mathrm{~mm}, 17=0.5 \mathrm{~mm}$.

inner distal margin with three simple setae; palp with 4 articles, $1^{\text {st }}$ distal outer margin with long simple seta and distal inner margin with three simple setae; article 2 longer than wide, medial margin with long simple setae, distal outer margin with one strong and long bipectinate seta; article 3 inner and outer distal face with few bipectinate setae and simple setae at inner medial margin; dactylus ungiform, shorter than article 3, with one robust seta with spinules on the apex (Fig. 10).

Revista Brasileira de Zoologia 21 (2): 179-184, junho 2004 
Gnathopods. Gnathopod 1 much smaller than gnathopod 2; propodus length twice or more maximum width, with no setae on anterior border, antero-distal corner with a group of a long simple setae, inner distal margin with approximately six long simple setae in its superior half, inner medial surface with oblique row of 8-12 bifurcates plumoses setae and a few short spines, outer medial surface with two groups of five simple setae near the palm; dactylus strong, slightly smaller than palm, outer margin with unipectinate medial setae and inner margin with four simple marginal spines; palm transverse, slightly convex, bearing simple setae of various sizes, posterior distal corner with two spines with spinules placed on each side of a short lobe; lobe of carpus well developed, produced and forming a scoop-like structure, open to the medial side, outer border with several unipectinate setae, inner border with 6-8 plumose setae, antero-distal corner with 8-11 long simple setae; inner distal margin of merus with four long simple setae; inner distal margin of ischium with two long bipectinate setae (Fig. 11). Gnathopod 2 larger than gnathopod 1, but proportionally small in respect to the animal's body size; propodus ovate, antero-distal corner with 8-10 simple setae, postero-distal corner with three long simple setae, inner distal face with five simple setae, no setae on anterior border, and posterior border with groups of 2-4 simple setae; dactylus shorter than palm approximately two-thirds the length of the palm, inner face with minute submarginal spines and medial outer face with a bipectinate setae; palm of propodus nearly straight, oblique, anterior edge with a process and five spines with spinules, posterior distal corner poorly defined and three short stout teeth, margin with three long simple setae near posterior distal corner; carpus small, posterior lobe elongate, border with simple setae margin with setae with spinule, antero-distal corner with three simple setae; posterior distal corner of merus with simple setae; ischium with two bipectinate setae on posterior distal corner, inner margin distal with two bipectinate setae; basis with posterior margin with four simple setae and three groups of two bipectinate setae, posterior distal corner with two bipectinate setae and one simple seta (Fig. 12).

Pereiopods. Pereiopod 3 same size as 4 , and increasing gradually in size from 5 to 7 .

Uropods. Uropod 1 with peduncle longer than rami, dorsal margin with three spines with spinules and two simple distal setae; inner ramus longer than outer one, dorsal margin with three spines with spinules and five distal simple setae, two being longer than the other three, male without curved setae on inner side of the ramus; outer ramus with four spines with spinules and three distal simple spines, two of which are long (Fig. 13). Uropod 2 with peduncle longer than rami, with two simple spines and three stout dorsal spines with spinules, being one medium size; inner ramus a little larger than the outer one, dorsal margin with three spines with spinules and five distal spines (three with spinules and two simple); dorsal margin of outer ramus with four spines with spinules and with three more at the apex (one large simple, one medium with spinule and one small simple) (Fig. 14). Uropod 3 with peduncle almost as long as the ramus, with two distal spines with spinules at the dorsal corner; dorsal margin of single ramus with two groups of three setae, one being thick and with spinule and two spines being slender and simple; truncate apex with four long simple setae (Fig. 15).

Telson longer than wider, entire, with two distal spines with spinules and with two groups of three small submarginal setae with plumose apex, at each side of the telson (Fig. 16).

Female, adult length $3.4-4.6 \mathrm{~mm}$, similar to the male, except in respect to gnathopods 1 and 2 .

Gnathopod 1. Propodus dorsal surface with an oblique row of six bifurcate and plumose setae; inner distal margin with simple and variously sized setae; ventral surface with a group of five simple setae near the palm and one setae close to the posterior angle; antero-distal corner with a group of 8-9 long simple setae. Dactylus smaller than the palm, with an unipectinate seta at the medial anterior border and posterior margin with five spines, two at the medial region and three approximately at one-third from distal. Palm of propodus convex, having outer border more produced than the inner one, with simple setae of various sizes and having a small lobe with two simple, curved, robust spines at its posterior distal corner. Carpus as long as propodus, bearing a posterior lobe with border pectinate and with several plumose setae; antero-distal corner with four setae, the longest bipectinate. Inner distal margin of merus with four bipectinate setae. Ischium smaller than merus, with two setae, one bipectinate and the other simple, placed at posterior distal corner; postero-distal corner of base with three setae, of which two bipectinate and one simple (Figs 17-18).

Gnathopod 2 with propodus similar to gnathopod 1 of the female and much smaller than that of the male.

Etymology. The specific name dielaii is a posthumous compliment to Professor Dielai Carvalho Pereira, for his valuable dedication over the years to the growth and development of education in Brazil.

Discussion. Hyalella dielaii sp. nov. is distinguished from all the already known species of the genus by having round and proportionately small eyes; the inner plate of the maxilla 1 distinctly long and thin; the distal margin of the propodus of male gnathopod 2 almost straight, posterior distal corner of palm poorly defined, without forming a lobe, and the dactylus very short, approximately two-thirds the length of the palm; uropod 3, dorsal margin single ramus with two groups of three setae

\section{ACKNOWLEDGEMENTS}

Thanks are due to Dr. Cristiana Serejo and Dr. Idalina Maria Brasil Lima, Departamento de Invertebrados, Museu Nacional, Rio de Janeiro, for their valuable cooperation, whenever requested.

Revista Brasileira de Zoologia 21 (2): 179-184, junho 2004 


\section{REFERENCES}

BousfieLD, E.L. 1993. A contribution to the reclassification of neotropical freshwater hyalellid amphipods (Crustacea: Gammaridea, Talitroidea). Bolletino del Museo Civico di Storia Naturale di Verona, Verona, 20: 175-224.

GonZÁlez, E.R. \& L. Watuing. 2003. A new species of Hyalella

Received in 15.VII.2003; accepted in 16.III.2004. from Brazil (Crustacea: Amphipoda: Hyalellidae), with redescriptions of three other species in the genus. Journal of Natural History, London, 37 (17): 2045-2076.

SoAREs, C.M.A. 1977. Estudo ecológico da região de Itamaracá, Pernambuco, Brasil. II. Anfípodos das famílias Talitridae e Amphitoidae. Suplemento de SBPC, Ciência e Cultura, São Paulo, 29 (7): 808.

Revista Brasileira de Zoologia 21 (2): 179-184, junho 2004 